\title{
PROJETO INTERDISCIPLINAR EM CURSOS EAD: UMA HISTÓRIA DE SABORES OU SABORES DA HISTÓRIA?
}

\author{
SÃO PAULO/SP JUNHO/2018

\begin{abstract}
Andrea Borelli - UCS - andrea.borelli@cruzeirodosul.edu.br
Rosana Fernandez Medina Toledo - UCS - rtoledo@cruzeirodosul.edu.br

Marcos Andrei Ota - UNICID - marcos.ota@cruzeirodosul.edu.br
\end{abstract} \\ Tipo: Relato de Experiência Inovadora (EI) \\ Categoria: Conteúdos e Habilidades \\ Setor Educacional: EDUCAÇÃO SUPERIOR
}

\begin{abstract}
RESUMO
O presente trabalho relata uma atividade, na modalidade $E a D$, realizada com os alunos regularmente matriculados nos seguintes cursos: Curso de Ciências Sociais, Curso Superior de Tecnologia em Gastronomia e Curso de História, da Universidade Cruzeiro do Sul Virtual, em março de $2018 \mathrm{com}$ finalização em junho de 2018. A atividade teve como proposta a participação de um concurso virtual o qual denominamos "Uma História de Sabores." O objetivo geral do trabalho pautou-se na construção e preservação da identidade cultural e gastronômica das diversas regiões do Brasil assim como na possibilidade da vivência de uma atividade interdisciplinar. Neste trabalho também evidenciamos as metodologias ativas, como sendo uma concepção educacional que coloca os estudantes da graduação como principais agentes de seu aprendizado. A grande proposta desse método é aperfeiçoar a autonomia individual do estudante, desenvolvendo-o como um todo. Dessa maneira, ele será capaz de compreender aspectos cognitivos, socioeconômicos, afetivos, políticos e culturais.
\end{abstract}

Palavras-chave: concurso virtual; Licenciaturas, História; Gastronomia; Ciências Sociais; projeto interdisciplinar 


\section{O nascimento...}

As coordenações dos cursos de Gastronomia e História, na modalidade presencial, já realizam uma atividade prática e teórica que está em sua nona edição. A atividade consiste na integração dos conteúdos contemplados no primeiro semestre de cada curso nas disciplinas de Cozinha Internacional e História Contemporânea. Esta atividade pauta-se, sempre, nos conceitos da interdisciplinaridade apoiada na teoria de Fazenda (2015, p.11) em que relata que a vivência de um projeto interdisciplinar, coloca que "Interdisciplinaridade é uma nova atitude diante da questão do conhecimento, de abertura à compreensão de aspectos ocultos do ato de aprender e dos aparentemente expressos, colocando-os em questão. Exige, portanto, na prática, uma profunda imersão no trabalho cotidiano".

A atividade também contempla elementos da metodologia ativa em que em que o aluno é chamado a participar da formação de seu conhecimento de maneira ativa e dinâmica, sempre visando a estimular o mesmo na busca por respostas, problematizações e críticas, garantindo, assim, sua liberdade e autonomia. (LIMBERGER, 2013).

\section{O concurso...}

O Concurso denominado "Uma história de sabores", da Cruzeiro do Sul Virtual, que acontece entre 05 de março e 19 de junho de 2018, tem como objetivo criar oportunidade para o desenvolvimento e aprimoramento profissional dos alunos, estimulando também sua criatividade e desenvolvendo seu espírito inovador, ter a consciência de uma cozinha responsável e sustentável e estimular o gosto pela pesquisa histórica de caráter local, enfatizando a noção de que a experiência com sabores, carrega em si saberes sobre a experiência concreta dos indivíduos. Desta forma, esta experiência pode contribuir para uma formação diferenciada dos discentes de um curso fortemente operacional, como a Gastronomia e para cursos amplamente teórico, como as Licenciaturas em Ciências Sociais e História. Foram elencados como objetivos específicos do concurso: (i)promover o trabalho de pesquisa acadêmica e interdisciplinar; (II) expressar competências de ordem teórica e prática; (III) desenvolver, por meio de pesquisa, conhecimentos históricos da gastronomia brasileira; (IV) divulgação e envolvimento do Polo em atividades de ordem prática.

Para participar do concurso os alunos foram orientandos a preencher a ficha de inscrição e cadastrar o respectivo trabalho de pesquisa e receita no período de 5 de março a 5 de abril de 2018, conforme cronograma divulgado no lançamento da atividade. A Figura 1 representa as cinco etapas concebidas para estruturar o concurso, considerando desde a divulgação inicial até a fase final de análise dos trabalhos submetidos. 
Figura 1 - Etapas do concurso

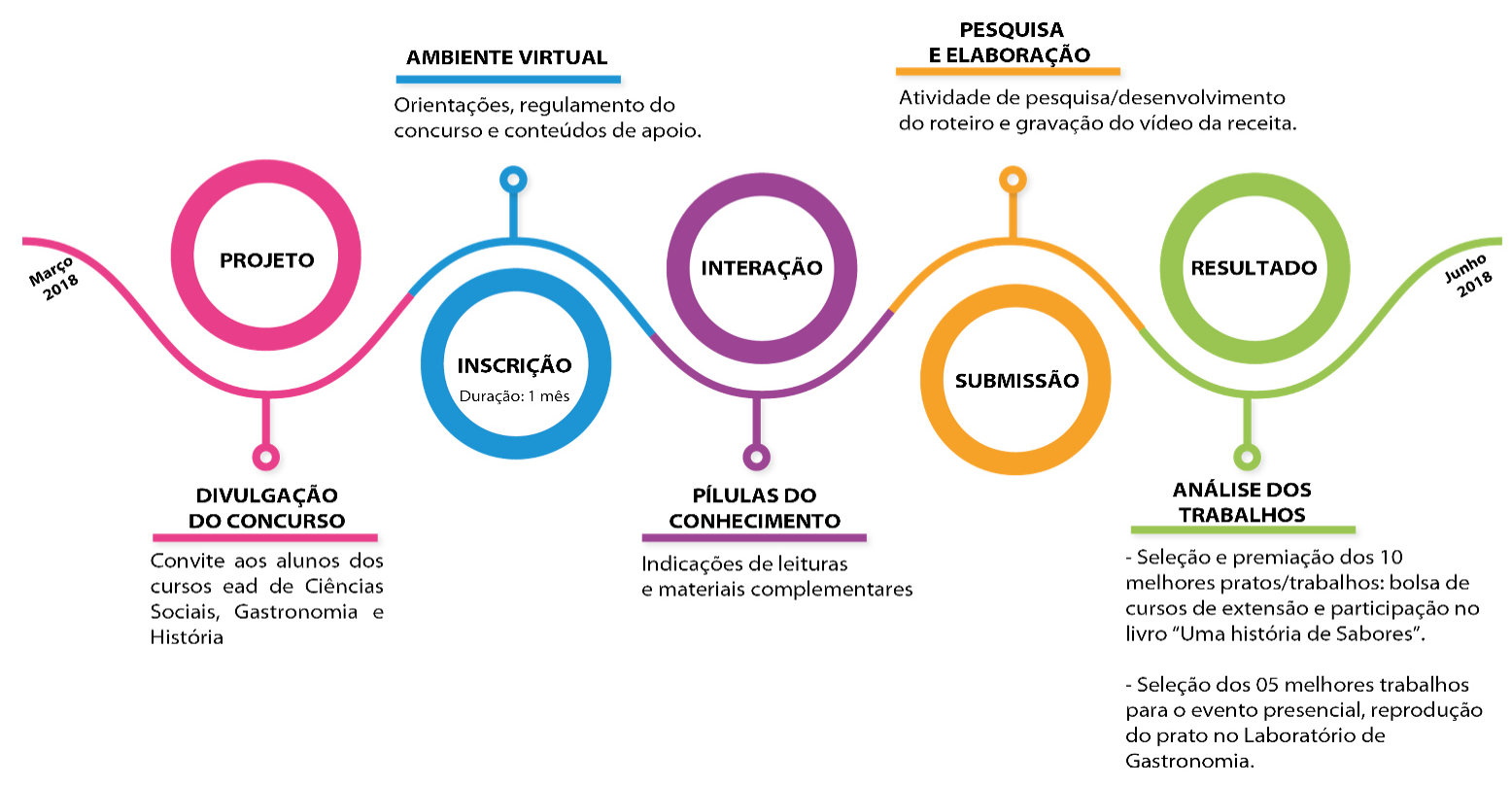

Fonte: Elaborado pelos autores.

Obrigatoriamente o trabalho tinha como exigência, os seguintes requisitos:

a. Desenvolvimento de um trabalho escrito (segundo as normas da ABNT) constando de contextualização sobre a herança cultural dos pratos escolhidos, fundamentando a escolha dos alimentos/preparações;

b. Elaboração de uma receita com contextualização dos ingredientes;

c. Criação da Lista de Compras dos ingredientes a serem utilizados;

d. Produção de 02 (duas) porções de cada prato para o julgamento final;

e. As receitas, na etapa presencial, deverão ser desenvolvidas para serem executadas no prazo máximo de $02 \mathrm{~h} 30$ horas e sem pré-preparo, tempo previsto para a duração do concurso;

f. É de livre escolha os ingredientes que serão providenciados pela Cruzeiro do Sul Virtual na etapa presencial, considerando a lista de compras elaborada pelo candidato.

Ao final do período de inscrição, 10 trabalhos foram selecionados por comissão interna da Instituição formada por docentes da Gastronomia, das Ciências Sociais e de História, segundo os critérios abaixo:

I. Referencial teórico: Produção de um artigo com introdução, apresentação da história e da receita e referências consultadas (Normas ABNT);

II. Vídeo de até 5 minutos apresentando a preparação da receita; 
III. Lista de compras (ingredientes) com as respectivas quantidades;

IV. Os 10 trabalhos selecionados serão divulgados pela comissão organizadora do concurso e passarão para a segunda etapa.

V. Os 05 melhores classificados virão a São Paulo para a etapa presencial e julgamento final da comissão.

VI. Os finalistas deverão chegar com 01 hora de antecedência ao horário, local e data estipulados pela comissão organizadora conforme cronograma, preparados para executar o prato e apresentar a história.

Ainda na etapa de análise dos trabalhos, a comissão julgadora do concurso avaliou os trabalhos dos participantes para realização da premiação dos 10 (dez) finalistas por meio da atribuição de pontuação, podendo chegar a um total de 100 (cem pontos) pontos, observados os seguintes critérios: trabalho escrito (50 pontos) e vídeo (50 pontos), descrevendo a produção da receita relacionada com o trabalho escrito. Diante da pontuação e respectiva classificação, a comissão escolheu entre os finalistas, os 05 melhores trabalhos para o evento presencial, previsto para 19 de junho de 2018, observandos os seguintes critérios: (i) organização da ilha de trabalho considerando higiene, manipulação segura, postura profissional e higiene pessoal: 50 pontos; (ii) apresentação da história da receita e sua importância regional: 50 pontos e (iii) serão selecionados os 5 (cinco) melhores trabalhos. A nota será composta pela avaliação da receita e da história.

Em caso de empate, a comissão observará a pontuação de categorias, na seguinte ordem:

I. Organização da ilha de trabalho considerando higiene, manipulação segura, postura profissional e higiene pessoal: 50 pontos;

II. Apresentação da história da receita e sua importância regional: 50 pontos.

III. Apresentação/Visual: se ainda houver empate, o participante que apresentar maior pontuação nessa categoria será o vencedor;

IV. Se ainda assim permanecer o empate, a decisão será tomada por consenso entre os jurados, sem possibilidade de recursos.

De forma geral e ancorado ao regulamento do concurso, algumas observações são necessárias para o compartilhamento do projeto:

a. A participação no Concurso é feita de forma gratuita e não está subordinada a qualquer modalidade de pagamento;

b. Os alunos participantes são responsáveis pela utilização não autorizada de 
receitas de terceiros em seus trabalhos e pelas consequências advindas pelo descumprimento da legislação vigente. Todos e quaisquer ônus por problemas de direitos autorais recairão exclusivamente sobre os responsáveis pela elaboração dos trabalhos;

c. Os alunos participantes autorizam a divulgação dos seus nomes, vozes e imagens, exclusivamente de interesse da comunicação, marketing e propaganda do concurso, bem como à divulgação cedem os direitos autorais de suas receitas (na íntegra ou em parte) à Cruzeiro do Sul Virtual que, por sua vez, poderão utilizá-la por prazo indeterminado, para fins que julgarem necessário, inclusive para publicações de livros, ou qualquer mídia seja impressa, audiovisual, eletrônica ou digital;

d. Os trabalhos escritos poderão ser difundidos pela Cruzeiro do Sul Virtual na íntegra ou em partes, para a divulgação do Concurso, por meio de qualquer mídia impressa, audiovisual, seja ela eletrônica ou digital;

e. $O$ preenchimento da ficha de inscrição e postagem do trabalho implica na aceitação integral deste regulamento por parte dos alunos participantes;

f. Os finalistas terão o direito de acompanhamento de um assistente denominado previamente determinado pela comissão. $\mathrm{O}$ assistente será um aluno do curso de gastronomia presencial;

g. As dúvidas não previstas neste regulamento serão dirimidas pela Comissão Organizadora do Concurso.

\section{Design e concepção pedagógica do projeto}

No que tange os aspectos de design e modelo pedagógico do projeto, tem-se na Figura 2 e 3 , a organização do conteúdo e as estratégias para promover o engajamento e a efetiva participação dos estudantes.

O desenvolvimento do modelo reuniu as contribuições dos princípios do Universal Design of Learning (UDL), sistematizadas pelos estudos de Rose e Meyer (2002), que apresentam o uso das estratégias do UDL alinhado às redes de aprendizagem (learning networks). Sendo elas: estratégias que suportam o reconhecimento da informação a ser aprendida; estratégias para processar a informação aprendida e estratégias para promover o envolvimento dos alunos nas tarefas. Tratando-se de estudantes dos polos da Cruzeiro do Sul Virtual que estão distribuídos geograficamente em estados brasileiros, buscou-se por meio de recursos midiáticos, demonstrar a riqueza histórica e cultural advindas de cada região. Além disso, o material didático produzido possibilitou o aprofundamento dos aspectos históricos enraizados na cultura gastronômica brasileira.

\section{Figura 2 - Design do projeto no ambiente virtual}




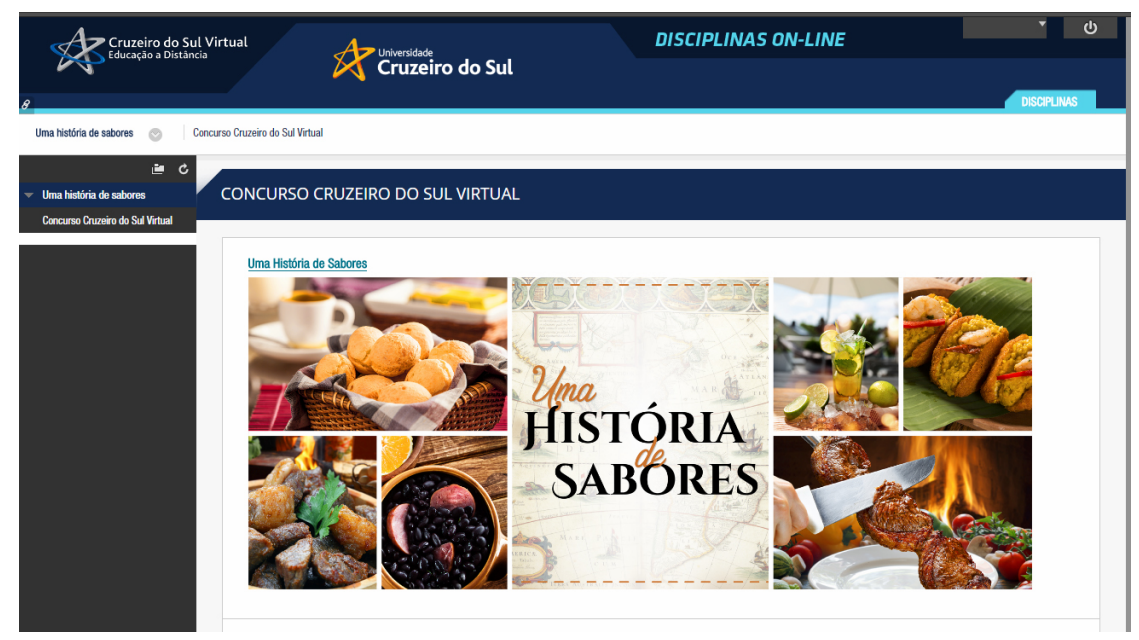

Fonte: Elaborado pelos autores.

Semanalmente, os alunos recebiam pílulas do conhecimento no ambiente virtual, contendo indicação de leitura, recomendações de vídeos e informações sobre História e Alimentação. Tal ação visou promover maior interação com os estudantes e ainda motivar a participação, demonstrando a relevância do projeto para o contexto dos cursos matriculados.

Figura 3 - Recursos didáticos e pílulas do conhecimento?

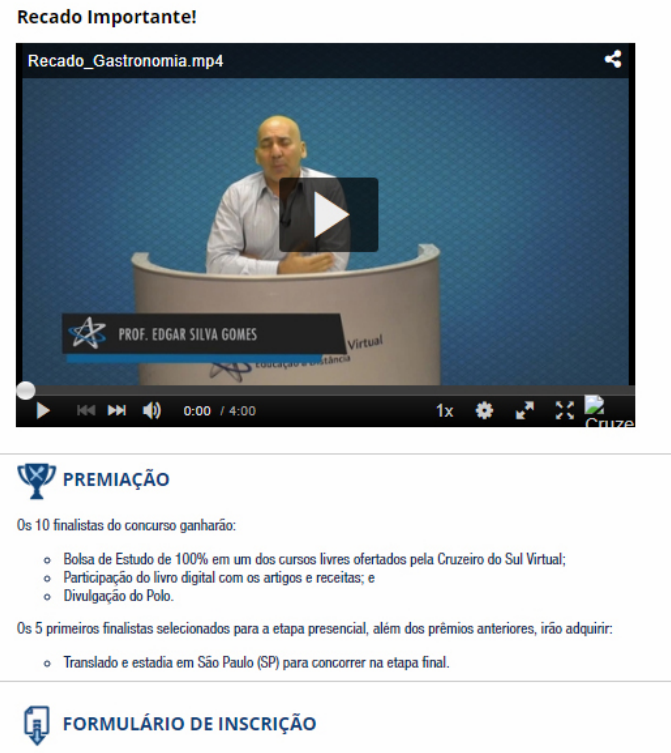

Fonte: Elaborado pelos autores.

A seguir, um exemplo de mensagens enviadas aos alunos, durante a fase de inscrição e submissão do concurso. 
As pesquisas nas áreas de história e gastronomia têm crescido muito nos últimos anos e, permitem conhecer novos aspectos do cotidiano. Selecionamos duas leituras que podem inspirar a participação de vocês em nosso concurso!

O artigo Alimentação e cultura material no Rio de Janeiro dos vice-reis: Diversidade de fontes e possibilidades de abordagens da Profa. Leila Mezan Algranti, que analisa alguns aspectos das práticas alimentares na cidade do Rio de Janeiro, na segunda metade do século XVIII

No artigo Maria Henriqueta Sperandio Garcia Gimenes-Minasse é discutido o conceito de Confort food, e suas principais características, partir de uma pesquisa bibliográfica.

Boa Leitura... Participe!!!

\section{Resultados parciais do projeto}

Como o projeto ainda está em andamento, tem-se alguns resultados parciais. Um total de 51 realizaram a submissão do trabalho, tendo como percentual $43 \%$ de alunos de História, $53 \%$ de Gastronomia e 4 \% representando o curso de Ciências Sociais.

\section{Gráfico 1 - Participação dos alunos por curso}

\section{Uma História de Sabores}

॥ História — Gastronomia @ Ciencias Sociais

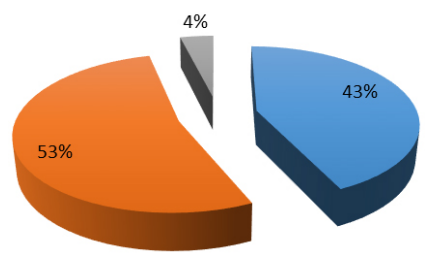

Fonte: Elaborado pelos autores.

A comissão julgadora realizou a avaliação dos trabalhos enviados e os 10 melhores trabalhos avaliados de acordo com os critérios de pontuação representam os estados (Figura 4): Acre, Brasília, Bahia, Minas Gerais, São Paulo e Rio de Janeiro. A saber, vale destacar que todos os trabalhos avaliados passaram também por critérios de qualidade do texto escrito, aspectos e relevância autoral, com verificação de recurso para plágio e originalidade da proposta do prato apresentado.

Figura 4 - Estados dos 10 melhores estudantes

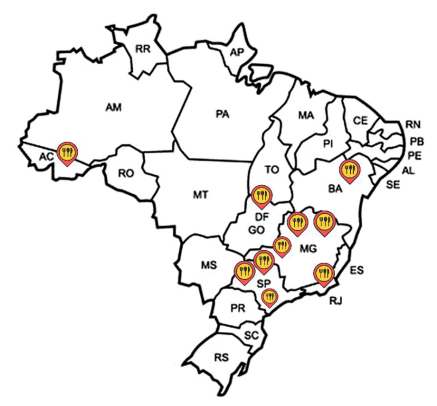


Fonte: Elaborado pelos autores.

O Quadro 1 apresenta a distribuição dos polos e as respectivas receitas escolhidas na classificação dos 10 melhores trabalhos. Os ganhadores serão contemplados com bolsas de estudo para cursos de extensão e ainda participarão do livro "Uma História de Sabores" sob organização dos idealizadores e coordenadores do projeto.

\section{Quadro 1 - Polo e as dez melhores receitas}

\begin{tabular}{|l|l|}
\hline Polo/Cidade do aluno & Receita \\
\hline Brasília/ DF & Pão de Mel \\
\hline Montes Claros/ MG & Pão de Queijo \\
\hline Oliveira - Carmo da Mata/ MG & Frango, Angu e Quiabo \\
\hline Tijuca - Rio de Janeiro/RJ & Papo de Anjo \\
\hline Guaratinguetá/SP & Afogado \\
\hline Santo Amaro - São Paulo/ SP & Godó de Banana \\
\hline Campinas/ SP & Feijão Tropeiro \\
\hline Araguari/ MG & Pão de queijo \\
\hline Pituba - Salvador-BA & Arroz Haussá \\
\hline Rio Branco/ AC & Costela de Tambaqui \\
\hline
\end{tabular}

Fonte: Elaborado pelos autores.

Dada a classificação, o Quadro 2 representa a classificação final dos 05 melhores trabalhos que participarão do evento presencial em junho de 2018 e reproduzirão o prato no Laboratório de Gastronomia do campus. Além do aspecto solene do evento de premiação, um ponto importante a se destacar, referem-se às ações para integração dos cursos e interação com os alunos do curso presencial de Gastronomia para apoiar os finalistas durante a elaboração do prato.

\section{Quadro 2 - Cinco melhores receitas}

\begin{tabular}{|l|l|}
\hline Polo/ Cidade do aluno & Receita \\
\hline Brasília / DF & Pão de Mel \\
\hline Tijuca - Rio de Janeiro/RJ & Papo de Anjo \\
\hline Santo Amaro - São Paulo/ SP & Godó de Banana \\
\hline Campinas/ SP & Feijão Tropeiro \\
\hline
\end{tabular}




\begin{tabular}{|l|l|}
\hline Polo/ Cidade do aluno & Receita \\
\hline Pituba - Salvador & Arroz Haussá \\
\hline
\end{tabular}

Fonte: Elaborado pelos autores.

Com intuito de partilhar, os resultados do projeto até aqui, tem-se no link: http://bit.ly/exemplo_historiasabores, um exemplo do trabalho desenvolvido e enviado por um dos alunos finalistas. A Figura 5 configura-se também como uma reflexão oportuna acerva do nível de engajamento que o projeto proporcionou aos estudantes dos cursos de Ciências Sociais, História e Gastronomia.

\section{Figura 5. Captura de Tela do vídeo gravado pelo aluno finalista}

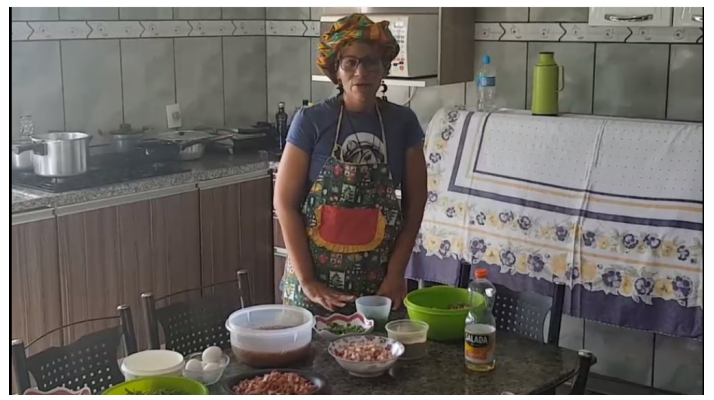

Fonte: Elaborado pelos autores.

Os resultados obtidos até aqui, demonstraram que o uso de tecnologias digitais na educação, não é um obstáculo com chances mínimas de superação, pensar em modelos de atividades ou projetos com uso de metodologias ativas que possam ampliar o engajamento dos estudantes, talvez seja o maior desafio.

Diante dessa afirmação, Amarilla Filho (2011) considera que a educação a distância implica uma dicotomia entre as tarefas dos processos de ensinar (estrutura organizacional, planejamento, concepção metodológica, produção de materiais) e dos processos de aprender (características e necessidades dos estudantes, modos e condições de estudos, níveis de motivação, etc.). Contudo, isso não significa que a EaD não possa diminuir as relações espaciais a favor do processo ensino-aprendizagem, ao contrário, definir o conceito de educação a distância e sua compreensão como modo de ensino é mais que defini-la como uma atividade de ensino e aprendizado sem que haja a proximidade física entre professor e aluno, aluno e aluno.

\section{Algumas considerações}

O objetivo desta ação é trazer uma experiência prazerosa, além de educativa aos envolvidos na atividade, permitindo conhecer outros aspectos da cultura que se 
pretende estudar:

\begin{abstract}
O gosto é, portanto, moldado culturalmente e socialmente controlado. O homem nasce em estado semifetal e necessita de um longo período de aprendizado, antes de integrar-se às estruturas sociais. Tal processo compreende a formação do gosto e dos hábitos alimentares. Assim, os alimentos habituais tornam-se objetos de predileção, os mais saborosos. Por isso, também, aprecia-se tanto os pratos da região em que se cresceu e, no terreno alimentar, predominam o chauvinismo e o conservantismo. A humanidade é mais conservadora em matéria de cozinha do que em qualquer outro campo da cultura. (FRANCO, 2001, p25)
\end{abstract}

Hoje, ao executar uma produção em laboratório, os profissionais da Gastronomia, devem abordar a história do prato e seu tempo histórico, as reações químicas dos ingredientes e sua finalização. Deve se pensar na teoria que sustenta essa prática para que haja questionamentos e construção de significados. O mesmo se aplica ao profissional das licenciaturas, cujo grande papel é dar sentido concreto as trajetórias humanas e ser capaz de produzir um conhecimento realmente transformador.

\title{
Referências:
}

AMARILLA FILHO, Porfírio. Educação a distância: uma abordagem metodológica e didática a partir dos ambientes virtuais. Educação em Revista. Belo Horizonte, v.27, n.02, p.41-72, ago.2011.

FAZENDA, I.C.A. (Org). Dicionário em construção: interdisciplinaridade. São Paulo: Cortez, 2015.

FRANCO, Ariovaldo. De caçador a gourmet. Uma história da gastronomia. São Paulo: Editora Senac. 2001.

LIMBERGER, Jane Beatriz. "Metodologias Ativas de Ensino-Aprendizagem para Educação Farmacêutica: um Relato de Experiência". Interface (Botucatu) [on-line], 2013, vol. 17, n. 47, pp. 969-975V. Disponível em < http://www.scielo.br/scielo.php?pid= S1414-32832013000400020\&script=sci_abstract\&tlng=pt> .Acessado em 2 abril 2018 ROSE, D. H. e MEYER, A.Teaching every student in the digital age: Universal design for learning. Alexandria: ASCD, 2002. 